\title{
PENGARUH PENGAWASAN TERHADAP PRODUKTIVITAS KERJA KARYAWAN BAGIAN PRODUKSI PT SUNSON TEXTILE MANUFACTURER
}

\author{
AI NUNUNG \\ Politeknik Piksi Ganesha \\ E-mail:hjan0967@yahoo.co.id
}

\begin{abstract}
ABSTRAK
This research is knowing effect on employee productivity monitoring the production of PT Sunson Textile Manufacturer, Supervision as an independent variable (x) and labor productivity as the dependent variable (y), and this study takes the number of respondents as many as 48 people. Data obtained through the questionnaire and then further processed to be tested through statistical analysis such as a simple regression nalysis, t-test and correlation analysis and determination with the help of using SPSP version 17. Result show than the results of t-test of hypothesis testing. $(5,757$ ) (2,013). This ni indicates that moitoring signifikan effect on the level of employee productivity. The amount of supervision on employee productivity in the production of PT Sunson textile manufacturer PT sunson Textile manufacturer Thorn is at $41,9 \%$.
\end{abstract}

Keywords : Monitoring, Work Productivity, PT Sunson Textile manufacturer

\section{A.PENDAHULUAN}

Era globalisasi sekarang memberikan pengaruh yang luar biasa bagi setiap Negara, salah satunya terjadi persaingan yang tajam ( Hyper competition ) antar Negara yang ada dibelahan bumi ini, yang menuntut ketangguhan system ekonomi bangsa bangsa untuk menjadi bagian dari system ekonomi dunia.

Dalam sebuah organisasi atau perusahaan, pengawasan yang ketat dan juga dibalik pengawasan dapat diberikannya motivasi dari pimpinan itu sendiri. Hal ini juga dapat menjadi pendorong timbulnya semangat kerja yang akhirnya berbuah prestasi bagi perusahaan itu sendiri. Begitu juga dengan halnya pelaksanaan pengawasan yang terdapat pada PT Sunson Textile manufacturer yang menjadi obyek penelitian ini, dimana manajer selaku pimpinan tertinggi dalam struktur organisasi seharusnya juga menerapkan pengawasan yang cocok dengan situasi dan kodisi yang sedang dihadapi.

Titik berat pengawasan sesungguhnya adalah MSDM ( Manajemen sumber daya manusia ), karena SDM itulah yang melakukan kegiatan-kegiatan dalam organisasi yang bersangkutan. Sesuai dengan fungsi adanya pemimpin, PT Sunson Textile Manufacture. juga memiliki beberapa jenis jabatan yang secara fungsionalnya sama halnya dengan seorang pemimpin, kita ketahui disetiap lokasi yang dimiliki oleh perusahaan ini memiliki seorang Kepala Departemen yang mana posisinya sebagai atasan dalam satu kawasan departemen tersebut, dan Kepala departemen tersebut membawahi kepala urusan yang tugasnya melakukan pengawasan pekerjaan yang dilakukan oleh kepala regu yang ada di bawahnya antara lain yaitu Operator.

Secara garis besar kepala Regu ini langsung berhadapan dengan karyawan pelaksana, secara umum seorang kepala Regu membawahi 5 s/d 6 orang karyawan pelaksana. Semua kepala Regu diatas bertugas mengawasi pekerjan karyawan pelaksana. Dan bentuk pekerjaan yang diawasi juga tentunya tidak sama dengan kepala Regu lain, namun ada juga beberapa bentuk pekerjaan yang kegiatan pengawasan yang sama. Seperti pada saat karyawan melakukan pekerjaan yang telah diberikan kepala Regu atau atasannya. Produktivitas karyawan dapat diketahui dari jumlah hasil yang diproduksi ( out put) dibagi dengan jumlah tenaga kerja (input). Secara umum seorang karyawan dikatakan berproduktivitas jika dalam melakukan pekerjaan mencapai standar pekerjaan yang telah ditetapkan perusahaan atau melampaui target yang diberikan sehingga prediksi perusahan untuk mendapatkan target yang diluar perkiraan perusahaan dan tentunya perusahaan mendapat efek yang luar biasa seperti meningkatkan pendapatan/output perusahan.

Oleh karena itu perusahaan harus melakukan pengawasan yang lebih ketat lagi agar tidak terjadi penyimpangan ataupun hal hal yang tidak diinginkan. Pelaksanaan pengawasan sangatlah penting dalam sebuah perusahaan, terutama terhadap karyawan. Pada dasarnya, setiap instruksi yang disampaikan kepada bawahan harus diawasi oleh pimpinan sehingga pimpinan pun mampu 
mengambil tindakan apabila ada terjadi kesalahan, kelalaian akan tugas yang dijalani oleh para karyawannya sehingga produktivitas karyawan semakin meningkat.

Berdasarkan penelitian awal maka dapat membuat suatu rumusan masalah dalam penelitian ini yaitu: Bagaimana pengaruh pengawasan Terhadap produktivitas kerja karyawan Bagian Produksi PT Sunson Textile Manufacturer.

\section{B. KAJIAN PUSTAKA}

1. Sumber Daya Manusia

Menurut FLIPPO dalam GOMES (2003:6) manajemen sumber daya manusia merupakan kegiatan perencanaan, pengorganisasian, pengarahan dan pengawasan kegiatan-kegiatan pengaduan, pengembangan, pemberian kompensasi, pengintegrasian, pemeliharan, dan pelepasan sumber daya manusia agar tercapai tujuan individu, organisasi dan masyarakat.

Manajemen sumber daya manusia terus berkembang sejalan dengan kemajuan dan tantangan jaman. Perkembangan yang harus diperhatikan dalam MSDM ini adalah kecenderungan-kecenderungan baru yang akan berdampak sangat positif terhadap perkembangan dan efektivitas organisasi. Jadi MSDM merupakan kegiatan perencanaan, pengadaan, pengembangan, pemeliharaan, serta pengguna SDM untuk mencapai tujuan yang baik secara individu maupun organisasi. Walaupun obyeknya sama-sama mausia dengan manajemen tenaga kerja atau dengan manajemen personalia ( Sutrisno, 2010:6)

2. Kepemimpinan

Menurut G. R Terry dalam terjemahan Winardi ( 2004 ) yang mengatakan kepemimpinan adalah hubungan dimana seseorang yaitu pemimpin mempengaruhi pihak lain untuk bekerja sama secara sukarela dalam mengusahakan ( mengerjakan ) tugas-tugas yang berhubungan, untuk mencapai hal yang diinginkan pemimpin tersebut.

3. Pengawasan

Menurut G. R Terry Mengemukakan," Control is to determinise what is accomplise , evaluate it, and apply corrective measures, if needed, to insur result in keeping with theplan". Pengawasan dapat diartikan sebagai suatu proses untuk menetapkan standar pekerjaan apa yang akan dilaksanakan, menilainya, dan perlu mengoreksi dengan maksud supaya pelaksanaan pekerjaan sesuai dengan rencana semula .( Manullang, 205:172)

Menurut stoner, Freeman, dan Gilbert (2000) menurut mereka control is the prosses of ensuring than actual activities conform the planned activities artinyapengawasan adalah proses untuk memastikan bahwa kegiatan yang sebenarnya sesuai kegiatan yang direncanakan, secara lebih lengkap Stoner, Freeman , dan Gilbert ( 2000) menyebutkan bahwa fungsi pengawasan dalam manajemen adalah upaya sistematis dalam menetapkan standart kinerja dari berbagai tujuan yang telah direncanakan, mendesain system informasi umpan balik, membandingkan antara kinerja yang dicapai dengan standart yang telah ditetapkan sebelumnya, menentukan apakan penyimpanagn dan tingkat signifikansi dari setiap penyimpangan tersebut, dan mengambil tindakan yang diperlukan untuk memastikan bahwa seluruh daya perusahaan dipergunakan secara efektif dalam pencapaian tujuan perusahan.

4. Pengertian Produktivitas

Menurut Siagian ( 2002 : 130 ) mengemukakan bahwa produktivitas merupakan suatu wilayah kegiatan organisasi yang selalu tampak sebagai salah satu sasaran jangka panjang artinya suatu perusahaan yang ingin tumbuh dan berkembang selalu berupaya menigkatkan produktivitas kerja sebagai sistem dalam organisasi tersebut, termasuk sistem manajemen, sistem fungsional dan sistem operasional.

Pendapat lain tentang produktivitas dikemukakan oleh Hasibuan ( 2003 : 94) adalah perbandingan antara output ( hasil ) dengan input ( masukan ). Jika produktivitas naik hanya dimungkinkan oleh adanya peningkatan effisiensi ( waktu, bahan ,tenaga ) dan sistem kerja, teknik produksi dan adanya peningkatan keterampilan dari tenaga kerjanya. 


\section{A. METODE PENELITIAN}

\section{Konsep pengukuran Variabel Penelitian}

Skala pengukuran yang digunakan dalam penelitian ini menggunakan Skala Likert. Skor jawaban respnden dalam penelitian ini terdiri dari lima alternative jawaban yang mengandung variasi nilai yang bertingkat dari obyek peneliian melalui jawaban pertanyaan dengan skor sangat setuju ( SS ) nilai 5, setuju ( S ) nilai 4 ,Cukup setuju ( CS ) nilai 3, tidak setuju (TS) nilai 2, sangat tidak setuju (STS) nilai 1. Untuk mengukur tingkat pengawasan dan produktivitas karyawan dari semua indikator, maka diajukan pertanyaan kepada responden sebanyak 27 pertanyaan dengan lima alternative jawaban seperti diatas. Untuk mengetahui kriteria pengawasan dan produktivitas digunakan skala interval dengan rumus yang digunakan Skala Likert. 4,20 - 5,00 sangat setuju sekali ( SS ) , 3,40 - 4,19 setuju ( s ), 2,60 - 3,39 Cukup setuju ( CS ) , 1,80-2,59 Tidak setuju ( TS ), dan 1,00 - 1,79 sangat Tidak Setuju ( STS ).

\section{Lokasi Penelitian}

Penelitian ini dilakukan di PT Sunson Textile Manufactuer yang terletak di JL Raya Rancaekek km 25,5 Kabupaten Sumedang yang bergerak di bidang Texstil

\section{Populasi dan sampel}

a. Populasi

Adapun dalam penelitian ini yang menjadi populasi yaitu berdasarkan bagian kerja produksi PT Sunson Textile Manufacture . sebanyak 48 orang yaitu terdiri dari bagian mekanik / elektrik, Roll Shoft, Maintenance, laboratorium ,Proses Shift I, Proses Shift II dan Proses Shift III

b. Ukuran sampel diketahui menggunakan rumus Slovin Hsein Umar ( 2009:78 ) yaitu :

$$
\begin{gathered}
n=\frac{N}{1+N e^{2}} \\
n=\frac{94}{1+94 x(10 \%)^{2}} \\
n=\frac{94}{1+94(0.1)^{2}} \\
n=\frac{94}{1+0.94} \\
n=\frac{94}{1.94} \\
n=48,45 \rightarrow 48 \text { orang }
\end{gathered}
$$

Keterangan :

$\mathrm{N}=$ Jumlah sample

$\mathrm{N}=$ Jumlah populasi

$\mathrm{e}=$ Persentase tingkat kesalah yang ditoleransi adalh $10 \%$

Dari hasil diatas dapat kita lihat hasilnya yaitu 48,45 ( dibulat menjadi 48 orang ). Jadi jumlah sampel yang diteliti yaitu sebanyak 48 orang ). Teknik ini dilakukan bila populasi mempunyai anggota/unsure yang tidak homogeny dan berstrata secara proporsioal ( Sugiyono, 2009 :118 )

\section{Jenis dan sumber data}
a. Data Primer
Data primer yaitu data dan informasi dari pengamatan langsung atau interview responden pada perusahaan ini, berupa tanggapan karyawan tentang fungsi pengawasan untuk meningkatkan produktifitas kerja karyawan pada PT Sunson Textile Manufacturer
b. Data Sekunder 
Data sekunder yautu data dan informasi dari perusahaan atau laporan yang dibuat oleh perusahaan atau laporan yang dibuat oleh perusahan seperti ; Jumlah karyawan, sejarah perusahaan, struktur organisasi dan aktivitas industry.

\section{Teknik Pengumpulan data}

Dalam mengumpulkan data yang diperlukan untuk penelitian ini, penulis melakukan teknik pengumpulan data sebagai berikut :

1. Interview yaitu metode pengumpulan data yang dilakukan dengan mewawancarai karyawan pabrik.

2. Kuesioner yaitu teknik pengumpulan data yang dilakukan dengan cara memberi seperangkat pertanyaan atas pernyataan tertulis kepada responden untuk dijawabnya ( Sugiyono $2004: 135$ )

\section{Analisis data}

Analisis data dalam penelitian ini adalah menggunakan metode deskriptip dan kuantitatif yaitu dengan mengolah data yang diperoleh dari perusahaan tersebut, kemudian dianalisis dengan menggunakan landasan teori sebagai alat untuk memecahkan masalah yang dihadapi kemudian mengambil sebuah kesimpulan.

\section{Analisis Regresi Linier Sederhana}

Analisis regresi linier sederhana adalah hubungan secara linier antara satu variable independen ( $\mathrm{X}$ ) dengan variable dependen ( $\mathrm{Y}$ ).

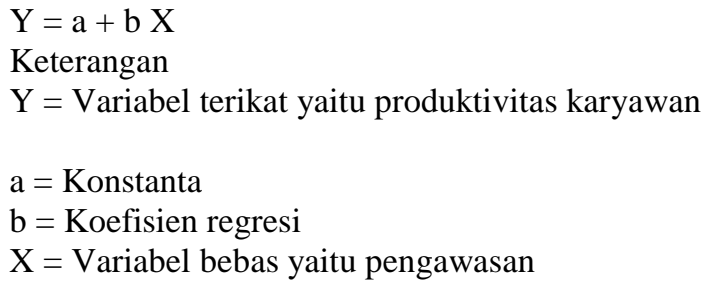

\section{Uji Instrumen}

\section{a. Uji Validitas}

Uji validasi digunakan untuk mengukur sah atau validnya suatu kuesioner . Suatu kuesioner dikatakan valid jika pertanyaan pada kuesioner mampu untuk mengungkapkan sesuatu yang akan diukur oleh kuesioner tersebut. Untuk menguji validitas kuesioner digunakan rumus statistika Koefisien Korelasi Produk Moment dari person yang dapat dicari melalui program SPSS . Untuk menguji validitas kuesioner digunakan dengan rumus sebagaii berikut :( Sugiyono, 2004:104 ).

$$
R x y=\frac{N \sum X Y-\left(\sum X\right)\left(\sum Y\right)}{\sqrt{\left(N \sum X^{2}\right)-\left(\sum X\right)^{2}} x \sqrt{\left(N \sum Y^{2}\right)-\left(\sum Y\right)^{2}}}
$$

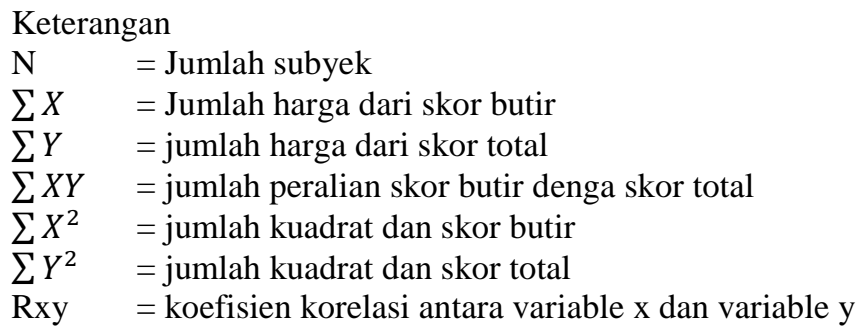

Jika produk $r$ produk tidak dapat disimpulkan bahwa instrument yang disimpulkan tidak valid, sebaliknya jika $\mathrm{r}$ hitung produk moment dapat disimpulkan yang digunakan valid.

\section{b. Uji Reabilitas data}


Menurut Santosa Budi Prabayu ( 2005 : 251 ) reabilitas sebenarnya adalah alat ukur untuk mengukur suatu kuisioner yang merupakan indikator dari variabel atau konstruk. Suatu kuisioner dikatakan realibel atau handal jika jawaban seseorang terhadap pertanyaan adalah konsisten atau stabil dari waktu ke waktu.

\section{Pengujian Hipotesis Koefisien Regresi}

Pengujian Hipotesis Koefisien Regresi bertujuan untuk memastikan apakah variabel bebas yang terdapat dalam persamaan regresi secara parsial dan simultan berpengaruh terhadap variabel terikat.

a. Uji t digunakan untuk menguji secara parsial atau individual pengaruh dari masingmasing variabel bebas yang dihasilkan dari persamaan regresi secara individu berpengaruh terhadap nilai variabel terikat.

b. Koefisien eterminasi ( R2 )

Karena dalam penelitian ini terdiri dari beberapa variabel, maka digunakan koefisien determinasi untuk mengukur besar sumbangan dari variabel bebas terhadap variabeel terikat. Semakin besar koefisien determinasi terkoreksi atau model regresi maka model yang didapatkan akan semakin baik.

B.

\section{HASIL PENELITIAN}

Penelitian ini dimulai dengan menebarkan kuesioner berbentuk daftar pertanyaan kepada karyawan PT Sunson Textile Manufacturer sebanyak 60 buah kuesioner yang disebarkan, selanjutya peneliti mengambil 48 kuesioner yang menjadi sampel dalam penelitian ini. Penelitian ini dilakukan selama 1 minggu mulai dari penyebaran kuesioner sampai pengembalian kuesioner.

\section{Analisis Deskriptif Pengawasan di PT Sunson Textile Manufacturer}

Sebagaimana yang telah diuraikan bahwa pengawasan adalah proses yang dilakukan dalam mengawasi, menilai dan mengevaluasi daripada seluruh kegiatan organisasi agar pekerjaan yang dilakukan dapat terlaksana dengan baik. Dengan adanya pengawasan yang dilakukan perusahaan maka akan menciptakan suatu produktivitas yang baik bagi pegawai, dimana produktivitas akan meningkat dan tujuan perusahaan dapat tercapai. Adapun factorfaktor yang mempengaruhi pengawasan karyawan adalah penetapan standart kerja, penilaian kerja dan mengoreksi pekerjaan.

Apabila faktor-faktor diatas dilakukan oleh seorang Kepala Urusan dalam melakukan pengawasan baik maka produktivitas karyawan secara tidak langsung dan dapat meningkatkan kinerja karyawan. Dari hal tersebut dapat terlihat bahwa indikator penelitian pengawasan masing masing mempunyai 3 (tiga ) buah pertanyaan. Dari pertanyaan ( indikator ) yang diajukan untuk mengukur pengawasan akan didapatkan hasil atau pembahasan tentang bagaimana tanggapan responden di PT Sunson Textile Manufacturer.

Gambaran mengenai pengawasan tersebut dijelaskan menggunakan teknik interval sehiingga tanggapan respinden dapat dikategorikan sangat setuju ( SS ) bobot nolai 5, Setuju ( S ) bobot nila 4, Cukup Setuju ( CS ) bobot nolai 3, Tidak setuju ( TS ) bobot nilai 2, Sangat tidak setuju ( STS ) bobot nilai 1. Pembahasan deskriptip pengawasan pada PT Sunson Textile Manufacturer dapat dilihat pada table-tabel berikut :

Tabel 4.1 : Rekapitulasi Indikator Pengawasan (X) Karyawan pada PT

\begin{tabular}{|l|l|l|l|}
\hline No & \multicolumn{1}{|c|}{ Sub Variabel } & Rata-rata & Keterangan \\
\hline 1 & netapan Standart Kerja & 3,47 & Setuju \\
\hline 2 & ilaian Kinerja & 3,36 & Cukup setuju \\
\hline 3 & ngoreksi pekerjaan & 3,38 & Cukup setuju \\
\hline
\end{tabular}




\begin{tabular}{|l|l|l|}
\hline Jumlah & 10,21 & \\
\hline Rata-rata & $\mathbf{3 , 4 0}$ & uju \\
\hline
\end{tabular}

Sumber : Data Olahan Peneliti 2018

Dari Penjelasan tabel diatas dapat kita lihat pernyataan responden terhadap pengawasan pada bagian produksi PT Sunson Textile Manufacturer .dikategorikan setuju karena nilai rata rata penilaian secara keseluruhan sebesar 3,40 ( Interval 3,40-4,19) . Dari tabel di atas dilihat bahwa indikator dari penilaian pekerjaan berada dalam kategori cukup setuju, hal ini harus lebih diperhatikan oleh perusahaan, dimana perusahaan harus lebih transparasi dalam melakukan bentuk penilaian yang akan dilakukan terhadap pekerjaan karyawan sehingga unsur-unsur pada tiap indikator pennilaian pekerjaan diatas menjadi lebih baik lagi pada masa yang akan datang.

\section{Analisis Produktivitas Kerja Karyawan pada bagian produksi PT Sunson Textile Manufacturer \\ Dengan adanya produktivitas diharapkan sebuah pekerjaan akan terlaksana secara efektif dan efisien, sehingga dipelukan target pencapaian yang telah ditetapkan oleh perusahaann agar tingkat produktivitas kerja karyawan dapat ditentukan dan diukur. Untuk mengukur produktivitas kerja karyawan maka ditentukan beberapa indikator yaitu :}

Tabel 4.2 Rekapitilasi Indikator Produktivitas ( Y )

Karyawan pada PT Sunson Textile Maufacturer

\begin{tabular}{|c|l|c|c|}
\hline & Sub Variabel & Rata-rata & Keterangan \\
\hline & kemampuan & 3,79 & Setuju \\
\hline & Penyelesaian tugas & 3,73 & Setuju \\
\hline & Semangat Kerja & 3,54 & Setuju \\
\hline & Tantangan Kerja & 3,56 & Setuju \\
\hline & Cara Menyelesaikan tugas & 3,36 & Setuju \\
\hline & Pengukuran Biaya Produksi & 3,26 & Cukup setuju \\
\hline \multirow{2}{*}{ Jumlah } & $\mathbf{2 1 , 5 3}$ & \\
\hline \multirow{2}{*}{ Rata-rata } & $\mathbf{3 , 5 8}$ & Setuju \\
\hline
\end{tabular}

Sumber : data olahan Peneliti, 2018

Dari penjelasan tabel 4.2 dapt diketahui pernyataan responden terhadap produktiitas karyawan pada bagian produksi PT Sunson Textile Manufacturer dikategorikan "setuju " karena rata-rata penilaian secara keseluruhan sebesar 3,58 ( Interval 3,40-4,19)

\section{Analisis Regresi Linier Sederhana}

Dari hasil tanggapan responden kemudian didistribusikan ke dalam program SPSS, untuk menganalisis data hasil penelitian ini dengan menggunakan analisis regresi linier sederhana maka pada tahap pertama yang dilakukan adalah melakukan pengujian kuesioner yang menggunakan uji validitas dan reabilitas.

Dari hasil perhitungan analisis linear sederhana dengan menggunakan program SPSS versi 17 diperoleh hasil sebagai berikut : 


\begin{tabular}{|l|c|l|l|}
\hline variabel & Koefisien regresi & T & Sig \\
\hline ( Constant ) & 30,734 & 5.138 & .000 \\
\hline Pengawasan & 1.108 & 5.757 & .000 \\
\hline $\begin{array}{l}\mathrm{R}=0,674 \\
\mathrm{R} \text { square }=0,419 \\
\text { Adjusted } \mathrm{R} \text { square }=0,406\end{array}$ & & \\
\end{tabular}

\section{Sumber : Hasil Olahan SPSS Versi 17, 2018}

Berdasarkan tabel diatas dapat diperoleh hasil regresi sebagai berikut :

$\mathbf{Y}=\mathbf{a}+\mathbf{b X}$

$\mathrm{Y}=30.734+1.108 \mathrm{X}$

$($ Produktivitas $=30,734+1,108)$ Pengawasan $)$

Keteranagan :

$$
\begin{aligned}
\mathrm{Y} & =\text { Produktivitas } \\
\mathrm{a} & =\text { Konstanta } \\
\mathrm{b} & =\text { Koefisien regresi variabel depeden } \\
\mathrm{X} & =\text { Pengawasan mandor }
\end{aligned}
$$

Nilai konstanta ( a ) sebesar 30,734 artiya adalah apabila variabel pegawasan diasumsikan nol ( 0 ) maka produktivitas sebesar 30,734. Nilai koefisien regresi variabel pengawasan sebesar 1,108 artinya adalah bahwa setiap peningkatan pengawasan sebesar 1 satuan maka akan meningkatkan produktivitas sebesar 1,108 . Persamaa diatas menunjukkan koefisien regresi dari variabel independent yaitu $b$ bertanda positif $(+)$, maka variabel pegawasan ( $\mathrm{X}$ ) berpengaruh terhadap produktivitas karyawan . Nilai $\mathrm{R}$ menunjukkan korelasi antara variabel independen dengan variabel dependen. Dan pada tabel diatas diketahui nilai $\mathrm{R}$ sebesar 0,647 artinya adalah bahwa hubungan antara pegawasan dengan produktivitas adalah kuat. Hal tersebut dapat kita lihat pada tabel berikut ini

Tabel 4.3 berikut ini :

\begin{tabular}{|c|l|}
\hline Koefisien Korelasi & Kategori \\
\hline $0,80-1,000$ & Keeratan hubungan sangat tinggi atau pengaruh sangat kuat /tinngi \\
\hline $\mathbf{0 , 6 0}-\mathbf{0 , 7 9 9}$ & Keeratan hubungan tinggi atau pengaruh kuat / tinggi \\
\hline $0,40-0,599$ & Keeratan hubungan sedang atau pengaruh sedang \\
\hline $0,20-0,399$ & Keeratan hubungan rendah atau pengaruh lemah \\
\hline $0,00-0,199$ & Keeratan hubungan sangat rendah atau pengaruh sangat lemah \\
\hline
\end{tabular}

\section{Uji Instrumen}

\section{a. Uji Validitas}

Adapun uji validitas yang dilakukan oleh peneliti dapat dilihat pada tabel 4.4. Besar nilai koefisien validitas ( $\mathrm{r}$ hitung ) dari setiap butir pertanyaan terlebih dahulu dibandingkan dengan besarnya nilai $\mathrm{r}$ pada $\mathrm{df}=5 \%$ yaitu : 


$$
\begin{aligned}
\mathrm{R} \text { tabel } & =\mathrm{df}:(\mathrm{n}-2) \\
& =5 \%:(48-2) \\
& =0,05 ; 46 \\
& =0,285
\end{aligned}
$$

Jika $\mathrm{r}$ hitung corrected item-total correlation $\geq \mathrm{r}$ tabel, maka item-item pertanyaan dinyatakan valid dan jika $r$ hitung $\leq \mathrm{r}$ tabel, maka item item pertanyaan dinyatakan tidak valid. Nilai $r$ hitung dalam uji ini adalah Pearson Correlation korelasi antara item dengan total skornya. Sedangkan nilai $r$ tabel dilihat pada tabel $r$ dengan persamaan $\mathrm{N}$ $2=48-2=46=0,285$. Artinya seluruh item-item variabel dinyatakan valid dandapat digunakan untuk penelitian ini.

\section{b. Uji reabilitas Data}

Reabilitas suatu konstruk variabel dikatakan baik jika memiliki nilai cronbach's alpha . dari 0,60 . Pengawasan 0,800 Reliable dan produktivitas 0,870 Reliable. Dengan demikian dapat disimpulkan bahwa item pertanyaan untuk variabel kinerja, desain pekerja, dan komperensi dinyatakan reliable dan dapat digunakan berkali-kali pada waktu yang berbeda.

\section{A. Pengujian Hipotesis Koefisien regresi}

a. Koefisien determinasi ( $\mathrm{r}$ 2)

Uji ini dilakukan untuk melihat seberapa besar persentase sumbangan pengawasan Kepala Urusan terhadap produktivitas karyawan. Pengukurannya adalah dengan menghitung angka koefisien determinasi ( r2 ). Diketahui nilai $\mathrm{R}$ square sebesar 0419 artinya adalah bahwa pengaruh variabel pengawasan terhadap variabel produktivitas karyawan pada bagian produksi PT Sunson Textile Manufacturer adalah sebesar 41,9\% sedangkan sisanya 58,1\% dipengaruhi oleh variabel lain yang tidak dimasukkan dalam model regresi ini contohnya seperti pada pelatihan pendidikan, promosi dan lain-lain.

Diketahui nilai t tabel pada taraf sigifikansi $5 \%$ ( 2-tailed ) denganpersamaan berikut :

$$
\begin{array}{ll}
\text { T tabel } & =\mathrm{n}-\mathrm{k}-1: \text { alpha } / 2 \\
& =48-1 \quad: 0,05 / 2 \\
& =46: 0,025 \\
& =2,013 \\
\text { Keterangan } & \mathrm{n}: \text { jumlah } \\
& \mathrm{K}: \text { Jumlah variabel bebas } \\
& \mathrm{I}: \text { Konstan }
\end{array}
$$

Dari tabel diatas diperoleh nilai $t$ hitung $>\mathrm{t}$ tabel $=5,757>2,013$ yang berarti $\mathrm{H}$ a diterima, artinya pengawasan berpengaruh signifikan terhadap produktivitas kerja karyawan bagian produksi pada PT Sunson Textile Manufacturer.

\section{SARAN}

Sehubungan dengan hasil penelitian yang telah disimpulkan di atas, peneliti merumuskan beberapa saran bagi para pembaca dan pada pihak PT Sunson Textile Manufacturer

1. Untuk meningkatkan produktivitas kerja karyawan, pengetahuan dan keahlian karyawan secara berkelanjutan sebaiknya PT Sunson Textile Manufacturer selalu membeikan pengawasan yang insentif kepada karyawannya agar produktivitas meningkat.

2. Didalam sub variabel penetapan standar kerja untuk mencapai produktivitas, maka sebaiknya atasan harus memberikan gambaran tujuan yang jelas agar pencapaian ketja tercapai sesuai harapan yang diinginkan.

3. Kesesuaian biaya produksi dengan banyaknya jumlah tenaga dan banyaknya kebutuhan yang dibutuhkan, karena dengan jumlah biaya produksi yang " cukup setuju ' 3,26 ( 
interval 2,60 - 3,39). Hal ini harus lebih diperhatikan oleh perusahaan dimana perusahaan harus lebih memperhatikan kondisi pekerjaan yang akan dikerjakan dengan melengkapi peralatan dan perlengkapan pekerjaan karyawan, sehingga karyawan aman dalam melakukan pekerjaannya dan hasil dari pekerjaannya juga lebih baik ddan target pencapaian perusahaan dapat tercapai denagn baik.

\section{DAFTAR PUSTAKA}

Gomes ,Faustino Cardoso . 2003. Manajemen Sumber Daya Manusia ,Andi.Yogyakarta

Griffin ,Ricky.W 2000. manajemen .Edisi Ketujuh, Jilid 2, Penerjemah Gina Gania ,Penerbit Erlangga .Jakarta .

Hasibuan, Malayu S. P . 2002 . Managemen Sumber Daya Manusia . Jakarta : Bumi Aksara.

Julitriarsa, Suprihanto. 2001. Manajemen Umum Suatu Pengantar Edisi Pertama.BPEE Yogyakarta, Yogyakarta .

Manulang . 2005. Dasar - Dasar Maanajemen .Gajah Mada University Press, Yogyakarta .

Nasution, 2006. Manajemen Mutu Terpadu, Bogor., Ghalia Indonesia.

Santosa Budi Prabayu .2005. Analisis Statistik degan Microsoft Exel dan SPSS, Yogyakarta.

Siagian, Sondang .2003. Teori dan Praktek Kepemimpinan, Rineka Cipta, jakarta.

Sinambela , D. Ester, 2010 . Pengaruh Lingkungan Berbelanja dan Pengalaman Berbelanja Terhadap Pembelian Tidak Terencana di Hypermarket GIANT . Jurnal , Pekanbaru.

Sjafri dan Aida, 2007 . Manajemen Mutu Sumber Daya Manusia , PT Ghalia Indonesia, Jakarta .

Stoner.J.A.F, Freeman RE, Gilbert DR ,2000, Manajemen ( terjemahan ) , Jilid I PT Prenhalindo, Jakarta.

Sugiyono . 2004 .Metode Penelitian Bisnis , CV Alfabeta, Bandung .

Sulistyani ,Ambar Teguh . 2004 .Memahami Good Govermance Dalam Perspektif Sumber Daya Manusia, Penerbit Gaya Media, Yogyakarta.

Sutrisno , Edy , 2010 , Manajemen Sumber Daya Manusia, Kencana, Jakarta.

Terry, George. 2000. Prinsip -Prinsip Manajemen, Edisi Bahasa Indonesia, Bumi Aksara, bandung.

Umar Husein, 2003 .Metode Penelitian Untuk Skripsi dan Tesis Bisnis, Raga Grafindo Perkasa, Jakarta. 